\title{
Mining the Feed Effects on Five Weeks Old Broiler Chicken
}

\author{
M. Alam ${ }^{1}$, M. Ohid Ullah ${ }^{2}$, Mirajul Islam ${ }^{2}$ and M. Shahidul Islam ${ }^{2 *}$ \\ ${ }^{l}$ Department of Agricultural Statistics, Sylhet Agricultural University, Bangladesh \\ ${ }^{2}$ Department of Statistics, Shahjalal University of Science \& Technology, Bangladesh
}

\begin{abstract}
Fattening the broiler chicken at lower age for better profit is the main focus of farmers who resort to various feeds to reach their goal. Any adverse effect in chicken's body through feed might produce health hazard to the consumers. Therefore, it is important to discover the concentration level of bio-chemical parameters in chicken's body due to different types of feeds available in the market. The study was conducted on seventy chickens which were randomly allocated to provide two types of feeds. Blood samples were taken at $35^{\text {th }}$ dayand readings for lipid profiles, liver enzyme parameters along with calcium and creatinine were determined through lab experiment. Analysis and graphs indicated that the feed provided by the hatcher produces significantly higher weight. Nevertheless, multivariate analysis of variance revealed that lipid profile levels and liver functioning were significantly different for two types of feed. A reflective mode partial least squares path model (PLSPM) indicates health status (as measured by weight and calcium) has significant effect on lipid profile level, although the other paths representing lipid profile and health status to liver functioning were not found to be significant. Moreover, we observed different PLS coefficients for two types of feeds but possessing same pattern of relationship.
\end{abstract}

Keywords: Broiler, Lipid profile, Liver function, Multivariate analysis of variance and PLS Path Modelling.

\section{Introduction}

In Bangladesh poultry industry is one of the major livestock sub-sectors which can ensure to supply cheap sources of good quality nutritious animal protein to the nation. Poultry meat contributes approximately 37 percent of the total animal protein in Bangladesh [1]. Improving body weight and feed efficiency of the birds is the main objective of the poultry meat industry since many years. There are other parameters, such as low cholesterol and improved fatty acid profile, which need to be taken into consideration [2].

A high level of toxic elements of blood and also lipid profile (i.e., total cholesterol) level in the chickens' body can eventually lead to serious consequences on consumers' health. The concentration levels of these blood parameters are changeable due to different types of poultry feeds. Lipid profile is the risk indicators of coronary heart disease [3].Lowering blood cholesterol concentration dietary monounsaturated fatty acids (e.g. oleic) were very effective and may be important in preventing coronary heart disease [4].

The effect of feeding garlic powder (GP) on the performance, digestibility, digestive organs and lipid profile of broilers were inspected [5] and found that GP could provide positive advantages in broilers performance as it significantly decreased total cholesterol (COL), triglycerides (TG), low density lipoprotein (LDL) and increased high density lipoprotein (HDL) levels compared to control birds and these result supported the findings of [6]. The effects of alpha lipoid acid on the performance and serum lipid profile in broiler chicken was found to have no effect on serum cholesterol, triglycerides and VLDL-cholesterol levels, but reduced the LDL-cholesterol level and increased the HDL-cholesterol level of broilers compared to control group [7]. The effect of high diet feed on lipid profile levels on chickens was studied by [8]. Poultry species, age and breeding condition is known to affect cholesterol deposition ([9], [10], and [11]).

The food which is be free from all types of health hazards and have good taste and necessary nutritional diet for human growth and development is healthy food. Nowadays food security and food safety is the top most public health concern worldwide. Important aspects of food quality on health safety are destroyed by entering the hazardous type of pollution in the food chain. Increasing the LDL and total cholesterol level the risk of serious problem of human like as stroke, heart attack and atherosclerosis also increases. Since the poultry fattening at the lower age for better profit, it is important to know the concentration level of these above parameters at different types of feed of chickens as well as identify the available better feed in the market. Bearing in mind lack of available information of poultry feed effects on serum bio-chemical parameters, this study was undertaken to investigate the effect of feed on lipid profile, liver function and others parameters in chicken.

Lipid profile and liver function's readings were considered as group of variables while other measurements were regarded as univariate. As the data did not violate classical assumptions, simple t-tests were performed for univariate tests, whereas multivariate analysis of variance (MANOVA) was resorted for groupedvariables. Chickens' weight and some biochemical parameters were found to differ significantly for two types of feeds. PLSPM is a non-parametric approach resorted to investigate any simultaneous dependency of group of 
variables [12]. A reflective mode PLSPM revealed that health status has significant effect on lipid profile level; whereas lipid profile and health status do not play significant role on liver functioning. We observed different PLS coefficients for two types of feeds; however, the pattern of relationship was similar.

\subsection{Experimental units and treatments}

\section{Experimental Design And Method}

Randomly selected seventy broiler chicks from 600 (Cobb-500) were randomly distributed into two groups each belongs of 35 birds. Chicks were collected for the study belonged to the same batch and the same breeding stock, reared under strict hygienic and similar conditions. Rooms, brooder battery and cages were thoroughly cleaned with $2.5 \%$ phenol and subsequently fumigated with formaldehyde gas. Sunlight and electric bulbs were used as source of heat and light, electric fan were used for controlling the room temperature. Birds of the both groups were vaccinated against disease according to the direction of the expert of the poultry science department of Sylhet Agricultural University (SAU), Sylhet, Bangladesh. Two different feed i.e., Feed A (Standard feed available in Market), Feed B (Supplied by Hatcher) for each stage (i.e., starter, grower and finisher) were supplied to the two groups from the first day to $35^{\text {th }}$ day of the experiment. Water was supplied ad labium during the entire experimental period. Composition of the diets and its nutrient composition for the above-mentioned phases are presented below.

Table 1. Ingredients and nutrient compositions of experimental diets

\begin{tabular}{|c|c|c|}
\hline Nutrient compositions & Feed A & Feed B \\
\hline \multicolumn{3}{|c|}{ Starter period (day 01 to day 14 ) } \\
\hline Crude Protein & Min $21.50 \%$ & $22.00-23.00 \%$ \\
\hline Fat & Min $3.50 \%$ & $5.00-6.00 \%$ \\
\hline Crude Fibre & Max 5.00\% & $3.00-4.00 \%$ \\
\hline Moisture & Max $12.00 \%$ & $10.00-11.00 \%$ \\
\hline \multicolumn{3}{|c|}{ Grower period (day 15 to day 25 ) } \\
\hline Crude Protein & Min $20.00 \%$ & Min $21.00-22.00 \%$ \\
\hline Fat & Min $3.00 \%$ & $5.00-6.00 \%$ \\
\hline Crude Fibre & Max 5.00\% & $3.00-4.00 \%$ \\
\hline Moisture & Max $12.00 \%$ & $10.00-11.00 \%$ \\
\hline \multicolumn{3}{|c|}{ Finisher period (day 26 to day 35 ) } \\
\hline Crude Protein & Min $19.00 \%$ & Min $21.00-22.00 \%$ \\
\hline Fat & Min $3.00 \%$ & $5.00-6.00 \%$ \\
\hline Crude Fibre & Max 5.50\% & $3.00-4.00 \%$ \\
\hline Moisture & Max $12.00 \%$ & $10.00-11.00 \%$ \\
\hline
\end{tabular}

\subsection{Collection of blood sample for the bio-chemical parameters}

From the wing veins of every bird of eachgroup's $3 \mathrm{ml}$ blood sample were collected for lipid profile, liver function and other bio-chemical parameter test at $35^{\text {th }}$ day age of chicken. We collected blood sample with the help of expert personnel at very early morning for fasting stage of the bird and also measured the weight of each sampled bird. Blood samples were transferred to the physiology laboratory of SAU, Sylhet within two hours of collection and serum were separated by centrifugation $(3000 \mathrm{~g}$, for 10 minutes at room temperature) and stored in eppendorf tubes for analysis.

\subsection{Studies of bio-chemical parameters of blood}

The chemistry semi-auto analyzer AUTOPAK was used for the concentrations of the biochemical parameters estimation by routine methods. Commercially available kits (RANDOX, County Antrim, United Kingdom) were used to analyse the serum for total cholesterol (TC) in enzymatic endpoint method, total triglycerides (TG) in GPO-PAP method, low density lipoprotein (LDL) in enzymatic (colorimetric) method, high density lipoprotein (HDL), calcium in colorimetric method, creatinine in colorimetric method and values were expressed as $\mathrm{mg} / \mathrm{dL}$. Furthermore, aspartate amino transferase (AST) and alanine amino transferase (ALT) for liver functioning were measured and expressed as U/L.

\subsection{Methodology}

Exploratory analyses as well as inferential analysis t-test, ANOVA and MANOVA were applied using the data obtained from the laboratory experiment for the difference of two groups according to two feeds due to individual blood parameter and also clustered parameters. PLS-PM was applied to get an idea of how the set of dependent variables are systematically explained by their sets of predictors i.e., to obtain score values of latent variables for prediction purposes.

In PLSPM, we considered the observed data set $\mathrm{X}$ constituted in 3 (mutually exclusive) blocks as $\mathrm{X}_{1}=$ health status which contains variables weight and calcium of serum, $\mathrm{X}_{2}=$ lipid profile which contains variables TC, TG, LDL and $\mathrm{X}_{3}=$ liver function which contains variables ALT, AST. Since the indicators HDL 
plausibly generate opposite effect from all others indicators of lipid profile, we exclude this from lipid profile block.Each block $X_{j}$ is assumed to be associated with a latent variable $L V_{j}$. The latent variables are estimated as a linear combination of their manifest variables (indicators of block). Moreover, an estimated $L_{\mathrm{j}}$ is called a score, which we denoted as:

$$
\widehat{\mathrm{LV}}_{\mathrm{J}}=\mathrm{Y}_{\mathrm{j}}=\sum_{\mathrm{k}} \mathrm{w}_{\mathrm{jk}} \mathrm{X}_{\mathrm{jk}} \quad \text { - - (1) }
$$

where $\mathrm{k}$ is the number of indicators of blocks. Our overall model in structural relationship is as follows:

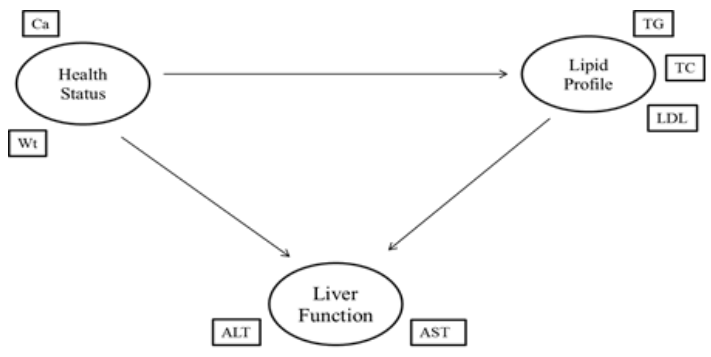

The Structural Model in mathematical notation can be written as:

$$
\mathrm{LV}_{\mathrm{j}}=\beta_{0}+\sum_{\mathrm{i} \rightarrow \mathrm{j}} \beta_{\mathrm{ji}} \mathrm{LV}_{\mathrm{i}}+\text { error }_{\mathrm{j}}
$$

where the subscript $\mathrm{i}$ of $\mathrm{LV}_{\mathrm{i}}$ refers to all the latent variables that are supposed to predict $\mathrm{LV}_{\mathrm{j}}$, the coefficients $\beta_{\mathrm{ji}}$ are the path coefficients and they represent the "strength and direction" of the relations between the response $\mathrm{LV}_{\mathrm{j}}$ and the predictorsLV $\mathrm{i}_{\mathrm{i}}, \beta_{0}$ is just the intercept term, and the error $\mathrm{j}_{\mathrm{j}}$ term accounts for the residuals.

The Measurement Model: Mathematical notation of the outer model in reflective mode as:

$$
\mathrm{X}_{\mathrm{jk}}=\lambda_{0 \mathrm{jk}}+\lambda_{0 \mathrm{jk}} \mathrm{LV}_{\mathrm{i}}+\mathrm{error}_{\mathrm{j}} \quad \text { - - (3) }
$$

The structural coefficients were estimated by ordinary least squares in multiple regression of $Y_{j}$ on the $Y_{i}$ 's andloadings are preferably calculated as correlations between a latent variable and its indicators as $\widehat{\lambda_{\mathrm{k}}}=$ $\operatorname{cor}\left(\mathrm{X}_{\mathrm{jk}}, \mathrm{Y}_{\mathrm{j}}\right)$. All of these analyses were done using statistical software R and SPSS.

\subsection{Exploratory data analysis}

\section{Results And Discussion}

We resorted to boxplots of all the variables for exploratory data analysis. The boxplot in Figure 1(a) shows that different median levels of weights were produced by two types of feeds. Figure 1(b) shows that the calcium levels are almost similar for two feeds, although there are couple of outlying observations for feed A.
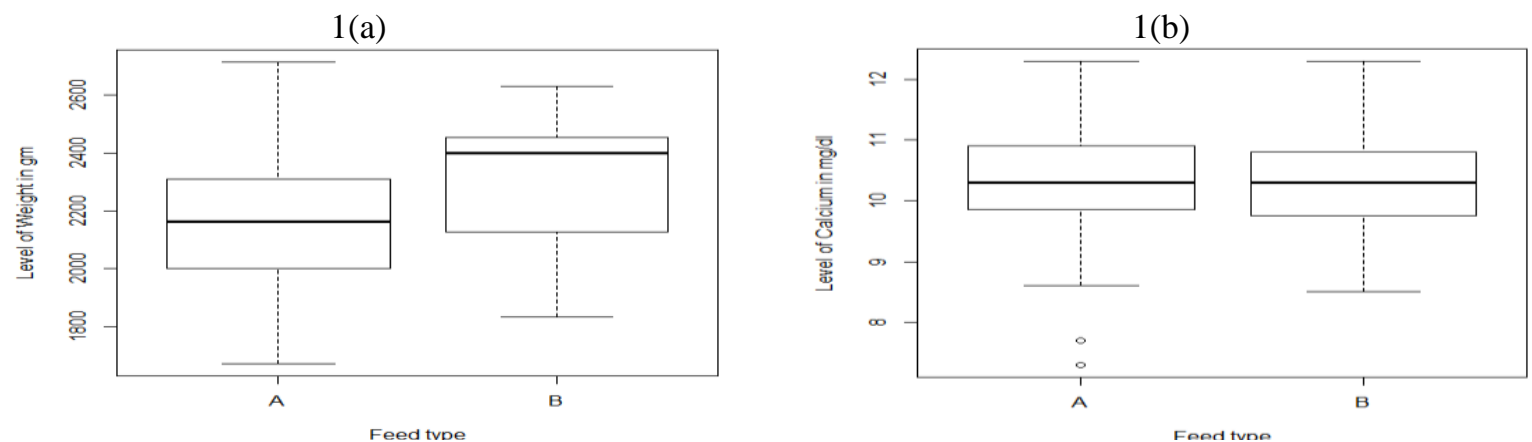

Figure 1. Box-plot for distribution of weight and calcium levels for two types of feed.

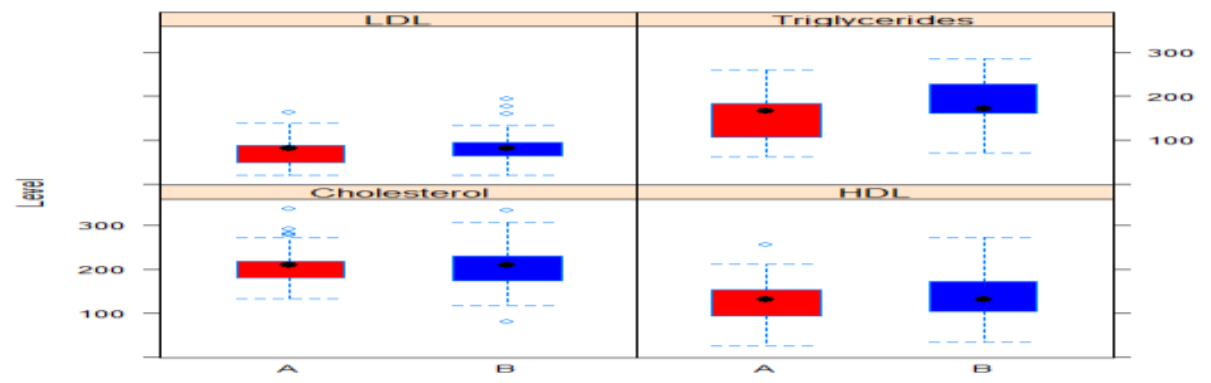


Figure 2. Box-plot for distribution of chicken's serum lipid profile levels for two types of feed. Color blue correspond to feed $\mathrm{A}$ and red to feed $\mathrm{B}$.

The boxplot in Figure 2 compares four indicators of lipid profile. These levels are not quite same for both type of feed, especially the boxplot for triglycerides demonstrated that feed A has apparently lower level. The boxplot of liver function parameters (Figure 3) shows that different types of feeds produce different median levels of ALT and AST. Moreover, there is much less variation in reading for ALT than in AST.

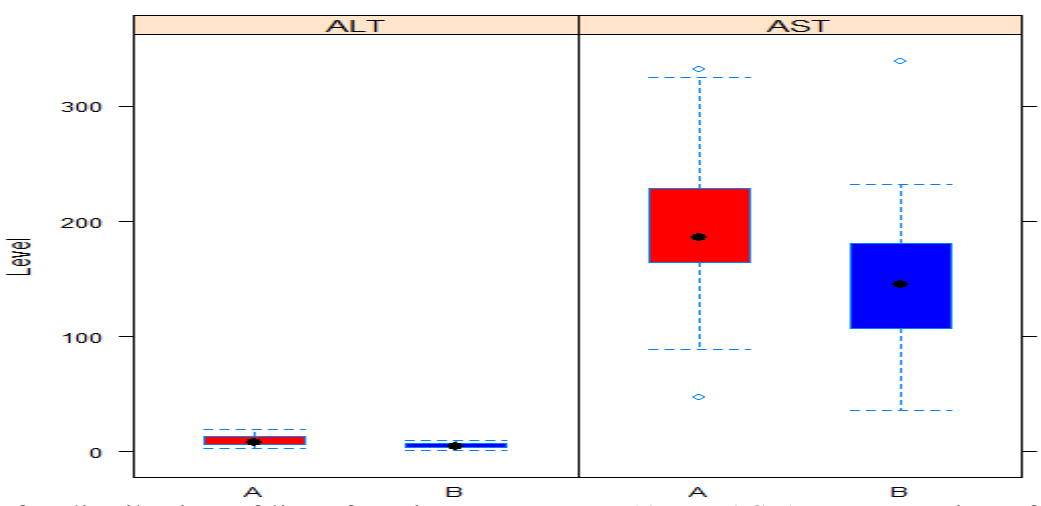

Figure 3. Box-plot for distribution of liver function parameters (ALT, AST) concentration of broilers serum for two types of feed.

\subsection{Inferential data analysis}

In inferential data analysis to facilitate the significance difference of biochemical parameters and their clusters due to two poultry feed we performed t-test and MANOVA.

Table 2. Effects of dietary supplementation on weight and biochemical composition (calcium and creatinine) of broiler chickens at finisher period

\begin{tabular}{|c|c|c|c|c|c|c|c|}
\hline \multirow[t]{2}{*}{$\begin{array}{c}\text { Blood } \\
\text { Parameters }\end{array}$} & \multirow[t]{2}{*}{ Feed } & \multirow[t]{2}{*}{ Mean \pm SE } & \multirow[t]{2}{*}{$\mathrm{T}$} & \multirow[t]{2}{*}{$\begin{array}{r}p- \\
\text { value }\end{array}$} & \multirow[t]{2}{*}{$\begin{array}{c}\text { Mean } \\
\text { difference }\end{array}$} & \multicolumn{2}{|c|}{$\begin{array}{l}95 \% \text { Confidence Interval for } \\
\text { mean difference }\end{array}$} \\
\hline & & & & & & Lower Bound & Upper Bound \\
\hline \multirow[t]{2}{*}{ Weight (gm) } & A & $2159.77 \pm 44.05$ & \multirow{2}{*}{$\begin{array}{r}- \\
2.631 \\
\end{array}$} & \multirow[t]{2}{*}{0.011} & \multirow[t]{2}{*}{-150.650} & \multirow[t]{2}{*}{-264.910} & \multirow[t]{2}{*}{-36.410} \\
\hline & B & $2310.43 \pm 36.58$ & & & & & \\
\hline \multirow{2}{*}{$\begin{array}{l}\text { Calcium } \\
(\mathrm{mg} / \mathrm{dl})\end{array}$} & A & $10.31 \pm 0.18$ & \multirow{2}{*}{$\begin{array}{c}- \\
0.095 \\
\end{array}$} & \multirow[t]{2}{*}{0.924} & \multirow[t]{2}{*}{-0.020} & \multirow[t]{2}{*}{-0.500} & \multirow[t]{2}{*}{0.460} \\
\hline & B & $10.34 \pm 0.15$ & & & & & \\
\hline \multirow[t]{2}{*}{ Creatinine } & A & $0.43 \pm 0.01$ & \multirow[t]{2}{*}{1.900} & \multirow[t]{2}{*}{0.062} & \multirow[t]{2}{*}{0.030} & \multirow[t]{2}{*}{-0.002} & \multirow[t]{2}{*}{0.064} \\
\hline & $\mathrm{B}$ & $0.39 \pm 0.01$ & & & & & \\
\hline
\end{tabular}

The mean weight of chickens was $2159.77 \mathrm{gm}$ and $2310.43 \mathrm{gm}$ for feed A and B respectively. Independent samples t-test in Table2 shows that the mean difference is significant for these two feeds. However, we did not find significant difference for the mean levels of calcium and creatinine.

Table 3. Effects of dietary supplementation on blood Lipid profile and Liver function of broiler chickens at finisher period (Multivariate Tests using Pillai's Trace)

\begin{tabular}{|l|l|l|l|l|}
\hline Effect & Response & F & p-value & Observed Power \\
\hline \multirow{2}{*}{ Feed } & Lipid profile (TC,TG,HDL \& LDL) & 3.50 & 0.012 & 0.840 \\
\cline { 2 - 5 } & Liver function (ALT \& AST) & 15.18 & 0.000 & 0.990 \\
\hline
\end{tabular}

Using the Pillai's Trace test of the multivariate analysis of variance (MANOVA), the lipid profile levels and the liver function level of poultry chickens were significantly different for two types of feeds. We were also interested in finding out the specific components of lipid profile and liver function that varied significantly and performed ANOVA in this regard.

Table 4. The influence of dietary supplementation on serum lipid profile and liver function of broilers

\begin{tabular}{|c|c|c|c|c|c|c|c|}
\hline \multirow[t]{2}{*}{ Blood Parameters } & \multirow[t]{2}{*}{$\begin{array}{l}\text { Types of } \\
\text { Feed }\end{array}$} & \multirow[t]{2}{*}{ Mean \pm SE } & \multirow[t]{2}{*}{$\mathrm{F}$} & \multirow[t]{2}{*}{$\begin{array}{c}\mathrm{p}- \\
\text { value }\end{array}$} & \multirow[t]{2}{*}{$\begin{array}{c}\text { Mean } \\
\text { difference }\end{array}$} & \multicolumn{2}{|c|}{$\begin{array}{l}\text { 95\% Confidence Interval fo } \\
\text { mean difference }\end{array}$} \\
\hline & & & & & & $\begin{array}{l}\text { Lower } \\
\text { Bound }\end{array}$ & $\begin{array}{l}\text { Upper } \\
\text { Bound } \\
\end{array}$ \\
\hline \multirow[t]{2}{*}{ Cholesterol (mg/dl) } & A & $209.46 \pm 7.63$ & \multirow[t]{2}{*}{0.00} & \multirow[t]{2}{*}{0.995} & \multirow[t]{2}{*}{-0.09} & \multirow[t]{2}{*}{-24.84} & \multirow[t]{2}{*}{24.67} \\
\hline & $\mathrm{B}$ & $209.54 \pm 9.78$ & & & & & \\
\hline \multirow{2}{*}{$\begin{array}{l}\text { Triglycerides } \\
(\mathrm{mg} / \mathrm{dl})\end{array}$} & A & $151.14 \pm 9.21$ & \multirow[t]{2}{*}{7.87} & \multirow[t]{2}{*}{0.007} & \multirow[t]{2}{*}{-34.74} & \multirow[t]{2}{*}{-59.46} & \multirow[t]{2}{*}{-10.03} \\
\hline & $\mathrm{B}$ & $185.89 \pm 8.28$ & & & & & \\
\hline
\end{tabular}


Mining The Feed Effects On Five Weeks Old Broiler Chicken

\begin{tabular}{|c|c|c|c|c|c|c|c|}
\hline \multirow[t]{2}{*}{$\mathrm{HDL}(\mathrm{mg} / \mathrm{dl})$} & A & $126.14 \pm 8.47$ & \multirow[t]{2}{*}{0.66} & \multirow[t]{2}{*}{0.419} & \multirow[t]{2}{*}{-10.34} & \multirow[t]{2}{*}{-35.73} & \multirow[t]{2}{*}{15.04} \\
\hline & B & $136.49 \pm 9.49$ & & & & & \\
\hline \multirow[t]{2}{*}{$\mathrm{LDL}(\mathrm{mg} / \mathrm{dl})$} & $\mathrm{A}$ & $77.51 \pm 6.38$ & \multirow[t]{2}{*}{0.94} & \multirow[t]{2}{*}{0.337} & \multirow[t]{2}{*}{-8.86} & \multirow[t]{2}{*}{-27.13} & \multirow[t]{2}{*}{9.41} \\
\hline & B & $86.37 \pm 6.57$ & & & & & \\
\hline \multirow[t]{2}{*}{ ALT(U/L) } & $\mathrm{A}$ & $9.89 \pm 0.83$ & \multirow[t]{2}{*}{25.21} & \multirow[t]{2}{*}{0.000} & \multirow[t]{2}{*}{4.66} & \multirow[t]{2}{*}{2.81} & \multirow[t]{2}{*}{6.51} \\
\hline & B & $5.23 \pm 0.42$ & & & & & \\
\hline \multirow[t]{2}{*}{$\mathrm{AST}(\mathrm{U} / \mathrm{L})$} & $\mathrm{A}$ & $198.06 \pm 11.29$ & \multirow[t]{2}{*}{12.99} & \multirow[t]{2}{*}{0.001} & \multirow[t]{2}{*}{55.51} & \multirow[t]{2}{*}{24.77} & \multirow[t]{2}{*}{86.26} \\
\hline & B & $142.54 \pm 10.48$ & & & & & \\
\hline
\end{tabular}

The results of the analysis of variance (Table4) revealed that only mean triglycerides was significantly different among the lipid profile parameters for two feeds. This also confirms the result [13] serum triglyceride level is important indicator of fat metabolism. On the other hand, both parameters observed in serum liver function i.e., mean ALT and mean AST level were significantly different for two feeds.

\subsection{Results of Partial Least Squares Path Modelling}

After performing PLSPM of reflective mode, we found the following structural relationship with significance values. In the inner model regression results demonstrated that the effect of health status is significant $(\mathrm{t}=3.520 ; \mathrm{p}=0.001)$ on the lipid profile but the effect of health status and lipid profile was not significant ( $\mathrm{p}=0.931$ and 0.108 respectively) on the liver function. The inner model path co-efficient (Figure4) revealed that the relationships between health status and lipid profile are positive while the relationship between other latent variable pairs are negative.

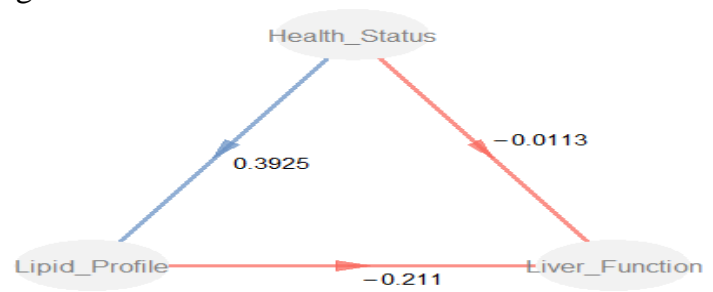

Figure 4: The PLSPM Path diagram of Lipid Profile and Health Status effect on Liver Function.

Figure 5 shows that the loadings of weight in health status block, triglycerides in lipid profile block and ALT in liver function block is greater than 0.7 , so these indicators considered as good/ acceptable indicators since they captured more than $50 \%$ variability by their latent construct.
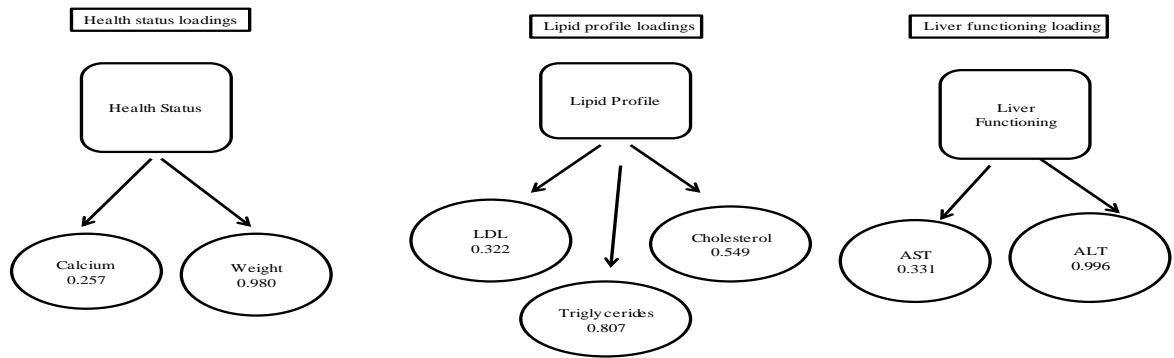

Figure 5: The outer model loadings of latent variables Health Status, Lipid Profile and Liver Functioning which shows the variability of the corresponding manifest variables.

Figure 6 reveals that the entire path coefficients for feed B were positive and path coefficients of lipid profile to liver function was negative which show inverse relationship between lipid profile and liver function for feed A. But the results of group comparisons analysis using t-test (Table 5) revealed that none of the path coefficients between the models for Feed-A and Feed-B are significantly different.

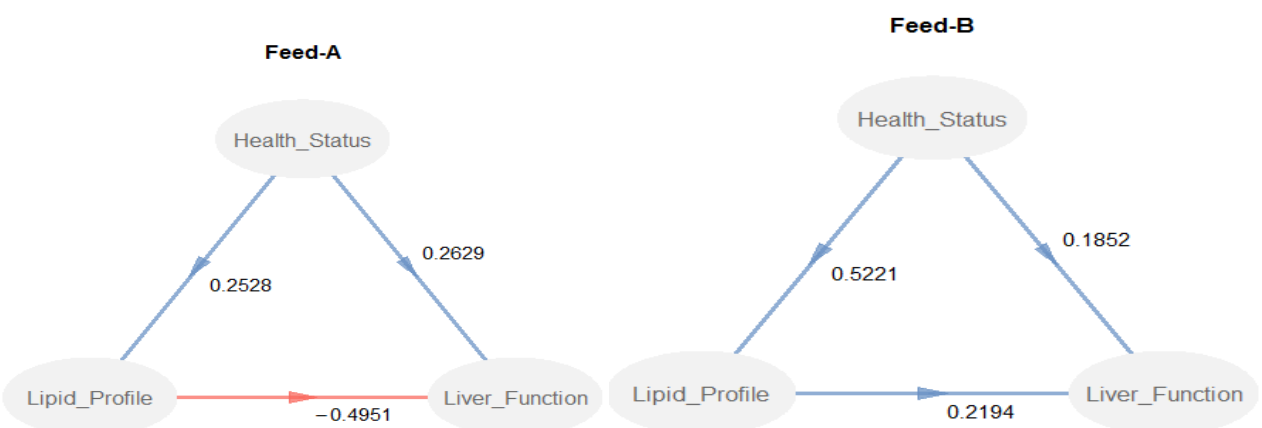


Figure 6: The PLSPM path diagram of Lipid Profile and Health Status effect on Liver Function due to Feed-A and Feed-B

Table 5. Group comparison in PLSPM for inner model coefficient using t-test (Permutation method)

\begin{tabular}{|l|l|l|l|l|l|}
\hline Latent variables / blocks & Global & Group A & Group B & Absolute diff. & p-value \\
\hline Health Status->Lipid Profile & 0.393 & 0.253 & 0.522 & 0.269 & 0.644 \\
\hline Health Status->Liver Function & -0.011 & 0.263 & 0.185 & 0.078 & 0.901 \\
\hline Lipid Profile-> Liver Function & -0.211 & -0.495 & 0.219 & 0.715 & 0.109 \\
\hline
\end{tabular}

\section{Conclusion}

Experiment was conducted on seventy randomly selected broiler chickens with requisite lab test to explore the feed effect on biochemical parameter of the chickens' body and some functional relationship among the components. Statistical analyses show that the feed provided by the hatcher produces significantly higher weight than that by other balanced feed available in the market which supported the findings of [8] that birds fed high diet (Crude protein and Fat) showed higher body weight (BW). However, similar test revealed no significant difference in the calcium and creatinine levels produced by two feeds. As the variables in lipid profile levels and liver functioning are in multivariate format, MANOVA results show that although higher weight was gained through the feed from hatcher, this feed significantly increases the lipid profile parameter of triglyceride level. Nevertheless, similar test uncovers that ALT and AST levels were significantly lower due to the feed provided by hatcher. To study the structural relationship among health status, lipid profile levels and liver functioning, a reflective mode path model was conducted. The PLS-Path model revealed that the effect of health status is significant on the lipid profile. Weight, triglycerides and ALT were the influencing indicators of health status, lipid profile and liver function respectively as they captured more than half of the variability. This analysis also indicated that patterns of the influence do not vary significantly while their effect was found different for the two types of feeds.

\section{Acknowledgments}

Authors are thankful to Research Centre of Shahjalal University of Science \& Technology, Sylhet, Bangladesh for funding and to the Department of Physiology and Toxicology \& Department of Poultry Science, Sylhet Agricultural University, Bangladesh for technical help and laboratory facilities rendered to this research work.

\section{References}

[1]. Islam, M. S. 2005. Comparative Performance of Sonali and Fayoumi Chickens from Day Old to Eight Weeks of Age with or without Supplementary Feeding. An Unpublished M.S. Thesis, Department of Poultry Science, Bangladesh Agricultural University, Mymensingh.-then start27-to 34

[2]. Nobar et al., 2010.Beneficial effects of canola oil on breast fatty acids profile and some of serum biochemical parameters of Iranian native turkeys. Journal of Cell and Animal Biology Vol. 4(8), pp. 125-130

[3]. Eqbal, M.A. et al., 2011. Natural Antioxidants, Lipid Profile, Lipid Peroxidation, Antioxidant Enzymes of Different Vegetable Oils. Advance Journal of Food Science and Technology 3(4): 308-316, 2011

[4]. Grundy SM. 1980. Comparison of mono-unsaturated fatty acids and carbohydrates for lowering plasma cholesterol. New England J. Med., 314: 745-748.

[5]. Issa, K. J. et al. 2012. Effect of garlic powder on performanance and lipid profile of broilers. Open Journal of Animal Sciences, Vol.2, No.2, 62-68

[6]. Prasad, R. et al. 2009. Lipid Profile of Chicken (Gallus domesticus) in Response to Dietary Supplementation of Garlic (Allium sativum). International Journal of Poultry Science 8 (3): 270-276

[7]. Murali, P., George Sherin, K. and George Dominic. 2014. Dietary Supplementation of Alpha Lipoic Acid on Serum Lipid Profile of Broiler Chicken Fed With Animal Fat Diet. International Journal of Genetic Engineering and Biotechnology. ISSN 09743073 Volume 5, Number 1 (2014), pp. 23-28

[8]. Tohala, S. H. 2010. The relationship between blood lipid profile and performance of broilers fed two types of finisher diets. Iraqi Journal of Veterinary Sciences, Vol. 24, No. 2, 2010 (87-91)

[9]. Hargis PS. 1988. Modifying egg yolk cholesterol in domestic fowl-a review. World's Poult. Sci. J., 44: 17-29.

[10]. Halle I. 1996. Effect of dietary fat on performance and fatty acid composition of egg yolk in laying hens. Arc. Fur. Gef., 60: 65-72.

[11]. Halle I. 2001. Effect of dietary fish oil and linseed oil on performance, egg component and fatty acid composition of egg yolk in laying hens. Arc. Fur. Gef., 65: 13-21.

[12]. Chin, W. W. 1998.The partial least squares approach for structural equation modeling,inG. A. Marcoulides (Ed.), Modern methods for business research. London: Lawrence Erlbaum Associates.

[13]. Zhan,et al., 2006. Effects of methionine and betaine supplementation on growth performance, carcass composition and metabolism of lipids in male broilers. British Poultry Science, 47: 576 - 580. 